\title{
NMR chemical shift pattern changed by ammonium sulfate precipitation in cyanobacterial phytochrome Cph1
}

\section{OPEN ACCESS}

Edited by:

John T. M. Kennis,

VU University Amsterdam,

Netherlands

Reviewed by:

Litao Sun,

The Scripps Research Institute, USA

Peter Hildebrandt,

Technische Universität Berlin

Germany

Shimon Vega,

Weizmann Institute of Science, Israel

${ }^{*}$ Correspondence:

Jörg Matysik,

Institut für Analytische Chemie, Universität Leipzig, Linnéstraße 3,

D-04103 Leipzig, Germany

joerg.matysik@uni-leipzig.de

Specialty section:

This article was submitted to

Biophysics,

a section of the journa

Frontiers in Molecular Biosciences

Received: 04 March 2015

Accepted: 06 July 2015

Published: 28 July 2015

Citation:

Song C, Lang C, Kopycki J, Hughes J and Matysik J (2015) NMR chemical shift pattern changed by ammonium sulfate precipitation in cyanobacterial phytochrome Cph1

Front. Mol. Biosci. 2:42. doi: 10.3389/fmolb.2015.00042

\author{
Chen Song ${ }^{1,2}$, Christina Lang ${ }^{3}$, Jakub Kopycki ${ }^{3}$, Jon Hughes ${ }^{3}$ and Jörg Matysik ${ }^{1,2 *}$ \\ 'Leids Instituut voor Chemisch Onderzoek, Universiteit Leiden, Leiden, Netherlands, ${ }^{2}$ Institut für Analytische Chemie, \\ Fakultät für Chemie and Mineralogie, Universität Leipzig, Leipzig, Germany, ${ }^{3}$ Institut für Pflanzenphysiologie, \\ Justus-Liebig-Universität Gießen, Gießen, Germany
}

Phytochromes are dimeric biliprotein photoreceptors exhibiting characteristic red/far-red photocycles. Full-length cyanobacterial phytochrome Cph1 from Synechocystis 6803 is soluble initially but tends to aggregate in a concentration-dependent manner, hampering attempts to solve the structure using NMR and crystallization methods. Otherwise, the Cph1 sensory module (Cph1 $\Delta 2)$, photochemically indistinguishable from the native protein and used extensively in structural and other studies, can be purified to homogeneity in $>10 \mathrm{mg}$ amounts at $\mathrm{mM}$ concentrations quite easily. Bulk precipitation of full-length Cph1 by ammonium sulfate (AmS) was expected to allow us to produce samples for solid-state magic-angle spinning (MAS) NMR from dilute solutions before significant aggregation began. It was not clear, however, what effects the process of partial dehydration might have on the molecular structure. Here we test this by running solid-state MAS NMR experiments on AmS-precipitated Cph1 $\Delta 2$ in its red-absorbing Pr state carrying uniformly ${ }^{13} \mathrm{C} /{ }^{15} \mathrm{~N}$-labeled phycocyanobilin (PCB) chromophore. 2D ${ }^{13} \mathrm{C}-{ }^{13} \mathrm{C}$ correlation experiments allowed a complete assignment of ${ }^{13} \mathrm{C}$ responses of the chromophore. Upon precipitation, ${ }^{13} \mathrm{C}$ chemical shifts for most of PCB carbons move upfield, in which we found major changes for $\mathrm{C} 4$ and $\mathrm{C} 6$ atoms associated with the $A$-ring positioning. Further, the broad spectral lines seen in the $A m S^{13} \mathrm{C}$ spectrum reflect primarily the extensive inhomogeneous broadening presumably due to an increase in the distribution of conformational states in the protein, in which less free water is available to partake in the hydration shells. Our data suggest that the effect of dehydration process indeed leads to changes of electronic structure of the bilin chromophore and a decrease in its mobility within the binding pocket, but not restricted to the protein surface. The extent of the changes induced differs from the freezing process of the solution samples routinely used in previous MAS NMR and crystallographic studies. AmS precipitation might nevertheless provide useful protein structure/functional information for full-length Cph1 in cases where neither X-ray crystallography nor conventional NMR methods are available.

Keywords: biliprotein, photoreceptor, phycocyanobilin, red-absorbing state, dehydration process, solid-state NMR 


\section{Introduction}

Phytochromes modulate various biological responses to light in almost all phases of plant development (Franklin and Quail, 2010). Plant phytochromes represent a paradigm for a large and diverse set of photochromic photoreceptors that are also known in many microorganisms (Kehoe and Grossman, 1996; Hughes et al., 1997; Yeh et al., 1997; Davis et al., 1999; Bhoo et al., 2001; Giraud et al., 2002; Froehlich et al., 2005; De Riso et al., 2009; Rockwell et al., 2014b). Phytochromes typically photoconvert between red-absorbing $(\mathrm{Pr})$ and far-red-absorbing (Pfr) states via a $C 15-Z / E$ isomerization of their covalently bound linear tetrapyrrole (bilin) chromophores (Rockwell et al., 2006; Hughes, 2010; Rockwell and Lagarias, 2010; Song et al., 2011a; Yang et al., 2011). The bilin chromophore such as phycocyanobilin (PCB), phytochromobilin ( $\mathrm{P} \Phi \mathrm{B})$, or biliverdin (BV) is buried in a conserved pocket formed in the GAF (cGMP phosphodiesterase, adenylate cyclase, FhlA) domain which is part of a knotted N-terminal photosensory module also comprising PAS (Period/ARNT/Single-minded) and PHY (phytochrome-specific) domains. The tripartite sensory module is conserved in canonical phytochromes and bacteriophytochromes (Wagner et al., 2005; Essen et al., 2008; Yang et al., 2008; Nagatani, 2010; Auldridge and Forest, 2011; Burgie et al., 2014). Phytochromes as well as a large group of related photoswitchable biliproteins, the cyanobacteriochromes (CBCRs) (Rockwell et al., 2011, 2012, 2014a; Chen et al., 2012; Hirose et al., 2013; Narikawa et al., 2013) have attracted increasing attention as in vivo fluorophores, in optogenetics and in synthetic biology (Shimizu-Sato et al., 2002; Levskaya et al., 2005, 2009; Shu et al., 2009; Tabor et al., 2009; Möglich and Moffat, 2010; Zhang et al., 2010; Lee et al., 2013; Müller and Weber, 2013; Müller et al., 2013, 2014a,b; Piatkevich et al., 2013; Tischer and Weiner, 2014; Yu et al., 2014; Ziegler and Möglich, 2015). Phytochrome absorbance and fluorescence at red to near-infrared wavelengths makes the superfamily interesting for studies involving whole, living organisms whose tissues scatter light particularly strongly at short wavelengths. Even more valuable is their peculiar photochromicity whereby two (meta)stable ground states with different absorbance maxima and physiological activities exist, thereby allowing biological processes to be switched on or off by a brief pulse of red or far-red light (Borthwick et al., 1952). Neither the photochromic absorbance properties nor its mechanistic connection to signaling are well understood, however.

Cyanobacterial phytochrome Cph1 from Synechocystis 6803 (Hughes et al., 1997; Yeh et al., 1997) represents the evolutionary link between bacteriophytochromes and plant phytochromes. The complete chromophore-bearing sensory module (amino acids 1-515) of the full-length holoCph1 (termed Cph1 $\Delta 2$ ) exhibits almost identical absorption spectra (van Thor et al., 2001) and photodynamics (Sineshchekov et al., 2002) to those of the native molecule. Cph1 $\Delta 2$ has proven to be an especially useful model for basic studies of structure/function relationship in full-length protein because of its tractability for the recombinant expression in Escherichia coli cells (Lamparter et al., 1997) and availability for biophysical studies including
X-ray crystallography (Essen et al., 2008; Mailliet et al., 2009) as well as both liquid-state (Strauss et al., 2005a; van Thor et al., 2006; Hahn et al., 2008) and solid-state (Rohmer et al., 2006, 2008, 2010a; Song et al., 2011a,b) NMR spectroscopy. These studies together with other physical and spectroscopic methods (van Thor et al., 2001, 2005; Dasgupta et al., 2009; Mroginski et al., 2009; Rockwell et al., 2009; Kim et al., 2012b, 2013, 2014a,b; Yang et al., 2012; Velazquez Escobar et al., 2015), and mutagenesis (Fischer and Lagarias, 2004; Strauss et al., 2005b; Hahn et al., 2006) have provided an improved mechanistic understanding of the phytochrome photosensor.

Cph1 $\Delta 2$ lacks the C-terminal transmitter module, comprising an ATP-binding/kinase domain as well as an amphiphilic helixloop-helix largely responsible for dimerization (Matsushita et al., 2003; Mateos et al., 2006) and a histidine phosphoacceptor proximal to the sensory module. Since there is no $3 \mathrm{D}$ structure of the complete structure of any phytochrome available (see Essen et al., 2008; Yang et al., 2008, 2009; Scheerer et al., 2010; Burgie et al., 2014; Takala et al., 2014), how the light signal is propagated from the bilin through the sensor module to affect the kinase/phosphotransferase activities of the transmitter module remains conjectural. Domain-swapping experiments with Cph1 and EnvZ, however, imply that the mechanism of intramolecular signaling in SHPK's (sensory histidine protein kinases) is conserved (Levskaya et al., 2005).

Attempts to solve the 3D structure of full-length holoCph1 have been impeded by concentration-dependent aggregation in solution. Psakis et al. (2011) found that glycerol/xylitol retards aggregation significantly, but does not prevent it. The problems associated with aggregation might be circumvented by precipitating the material using ammonium sulfate $(\mathrm{AmS})$ before it begins to aggregate, i.e., by collecting the SEC (size-exclusion chromatography) fractions directly into AmS. This procedure seems not to disturb the structure greatly, as the relative proportions of Pr and Pfr remain the same before and after AmS precipitation. Moreover, as previously described in full-length phyA phytochrome from Avena sativa, the low-temperature FTRR (Fourier-transform resonance Raman) spectra of AmS precipitates displayed similar vibrational band patterns to those of the frozen solutions (Matysik et al., 1995), implying that the effect of AmS precipitation is restricted to the hydration shell of the protein molecule. These relatively old FTRR data, however, would be insufficiently accurate to detect subtle modifications of the electronic structure of the bilin as well as its interactions with the direct binding pocket upon dehydration.

Previous MAS NMR studies on phytochromes used frozen solutions of highly concentrated proteins routinely, e.g., the complete sensory modules of Cph1 from Synechocystis 6803 and phyA3 from A. sativa (Rohmer et al., 2008, 2010a; Song et al., 2011a, 2012) as well as an isolated GAF-domain fragment of Cph2 from Synechococcus OS-B' (Song et al., 2014). Holoproteins of these phytochromes were produced by in vitro assembly with a uniformly ${ }^{13} \mathrm{C} /{ }^{15} \mathrm{~N}$-labeled PCB chromophore $\left(u\right.$ - $\left[{ }^{13} \mathrm{C},{ }^{15} \mathrm{~N}\right]$ PCB). Here, we use MAS NMR technique to assess whether the structure and immediate environment of the bilin in the $u$ - $\left[{ }^{13} \mathrm{C},{ }^{15} \mathrm{~N}\right]-\mathrm{PCB}$-holoCph1 $\Delta 2$ are preserved in an AmS pellet using $2 \mathrm{D}{ }^{13} \mathrm{C}-{ }^{13} \mathrm{C}$ dipolar correlation experiments which allow 
for a complete and unambiguous ${ }^{13} \mathrm{C}$ assignment for the entire bilin. We find that almost all of bilin signals move upfield (smaller chemical shifts) in the precipitated sample relative to those obtained from the frozen solution. The global effect induced by the partial dehydration on the bilin electronic structure can be attributed predominantly to packing effects between the bilin and its binding pocket. It is, however, unlikely to arise from the local modification of bilin interaction with specific protein residues.

\section{Material and Methods}

\section{AmS Precipitation of Cph1 12 as $\mathrm{Pr}$}

The $u-\left[{ }^{13} \mathrm{C},{ }^{15} \mathrm{~N}\right]-\mathrm{PCB}-$ holoCph1 $\Delta 2$ was prepared and purified by Ni-affinity and SEC as described (Song et al., 2011a). Working in dim blue-green safelight (490 nm LED), $37.5 \mathrm{ml}$ of cold AmS buffer (50 mM Tris; $3.3 \mathrm{M} \mathrm{AmS;} 1 \mathrm{mM}$ IDA, pH 7.8) was added to $15 \mathrm{mg}$ of this material in the Pr state (following saturating irradiation with $730 \mathrm{~nm}$ monochromatic red light) in $25 \mathrm{ml}$ TESß (50 mM Tris; $5 \mathrm{mM}$ EDTA; $300 \mathrm{mM} \mathrm{NaCl}$; $1 \mathrm{mM} \beta$ mercaptoethanol, $\mathrm{pH} 7.8$ ), gently mixed at $4{ }^{\circ} \mathrm{C}$ for $>24 \mathrm{~h}$. The precipitate was then pelleted at $10,000 \mathrm{~g}$ for $10 \mathrm{~min}$ at $4{ }^{\circ} \mathrm{C}$ and most of the supernatant removed. Following centrifugation at $50,000 \mathrm{~g}$, the pellet was finally suspended in $600 \mu \mathrm{L}$ of the original precipitant. This slurry was packed stepwise into a 4-mm zirconia MAS NMR rotor by centrifugation at $50,000 \mathrm{~g}$, the supernatant being removed after each spin. The final packed volume was $100 \mu \mathrm{L}$, comprising ca. $10 \mathrm{mg}$ of holoprotein. The rotor was then snap-frozen in liquid nitrogen and kept at $-80^{\circ} \mathrm{C}$.

\section{MAS NMR Spectroscopy}

Two-dimensional ${ }^{13} \mathrm{C}-{ }^{13} \mathrm{C}$ dipolar-assisted rotational resonance (DARR) experiments were used to assign ${ }^{13} \mathrm{C}$ chemical shifts of the $u-\left[{ }^{13} \mathrm{C},{ }^{15} \mathrm{~N}\right]-\mathrm{PCB}$ chromophore in Cph1 $\Delta 2$ as an AmS pellet. The DARR spectra shown in Figure 1 and Figure $S 1$ were recorded by using a DMX-400 spectrometer equipped with a 4mm CP/MAS probe (Bruker, Karlsruhe). The rotor containing the in vitro assembled holo-Cph1 $\Delta 2$ was cooled to $-50^{\circ} \mathrm{C}$ in the magnet. The DARR spectra were acquired at a MAS rate of $13 \mathrm{kHz}$ with two mixing times of 2 and $28 \mathrm{~ms}$ for ${ }^{13} \mathrm{C}$ homonuclear recoupling. During the mixing period, the ${ }^{1} \mathrm{H}-$ ${ }^{13} \mathrm{C}$ dipolar interaction was recovered by ${ }^{1} \mathrm{H}$ continuous wave irradiation with the intensity satisfying the $n=1$ rotaryresonance condition (Takegoshi et al., 2001). Two-pulse phasemodulated proton decoupling scheme (Bennett et al., 1995) was applied during free evolution and acquisition periods. The typical decoupling field strength was $84 \mathrm{kHz}$. The data were collected with an 8-ms evolution in the indirect dimension; 1434 complex $t_{2}$ and 128 real $t_{1}$ points with 2048 scans. A relaxation delay of $1.5 \mathrm{~s}$ was applied. Each spectrum was recorded over a period of $\sim 140 \mathrm{~h}$. Prior to Fourier transformation, the data were zerofilled to 4096 points, and an exponential apodization of $25 \mathrm{~Hz}$ was applied. ${ }^{13} \mathrm{C}$ resonances were externally referenced with respect to backbone $\mathrm{CO}$ signal of solid glycine. $\mathrm{HCl}$ at $176.04 \mathrm{ppm}$ on the TMS scale. The data were processed with Bruker Topspin 3.1 and further analyzed by using the Sparky 3.114 (Goddard and Kneller, 2008).

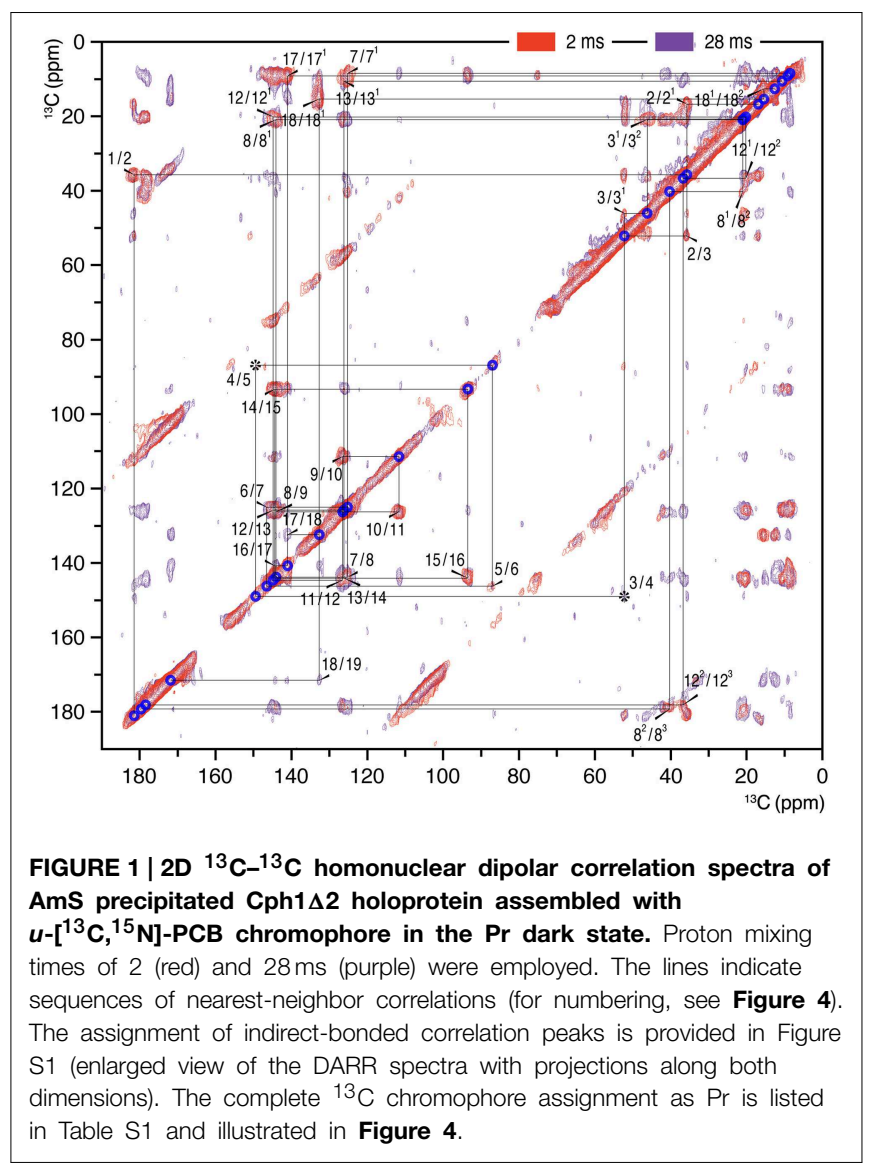

\section{Results}

2D ${ }^{13} \mathrm{C}-{ }^{13} \mathrm{C}$ correlation spectra of the AmS-precipitated $u$ $\left[{ }^{13} \mathrm{C},{ }^{15} \mathrm{~N}\right]-\mathrm{PCB}$-holoCph1 $\Delta 2$ in its red-absorbing Pr form were recorded for ${ }^{13} \mathrm{C}$ chemical shifts $\left(\delta^{\mathrm{C}}\right)$ of the bilin chromophore with two DARR mixing periods of 2 and $28 \mathrm{~ms}$ (Figure 1, red and purple, respectively; enlarged views of the spectra with external 1D projections along both dimensions shown in Figure S1). With a shorter mixing time of $2 \mathrm{~ms}$, the DARR spectrum (red) is dominated by correlations occurring between strongly coupled (e.g., directly bonded) spins, whereas the data acquired with a 28-ms mixing time (purple) also reveal weak, through space ${ }^{13} \mathrm{C}-{ }^{13} \mathrm{C}$ couplings (e.g., long-range distances). It should be noted that the DARR experiments on this sample with mixing times beyond $40 \mathrm{~ms}$ yield much decreased overall signal intensity with many expected correlations only partially resolved (e.g., C1-C3 correlation build-up curve shown in Figure 2, red). Whereas, in the frozen solution states of canonical phytochromes a mixing time of $50 \mathrm{~ms}$ was found to be optimal for revealing the long-range ${ }^{13} \mathrm{C}-{ }^{13} \mathrm{C}$ correlations (Rohmer et al., 2008; Song et al., 2012). Thus, DARR mixing in the precipitated sample shows a much faster build-up behavior for long-range correlations relative to the frozen one, indicative of a more efficient spindiffusion process between protons (Huster et al., 2002; Akbey et al., 2012). 
The ${ }^{13} \mathrm{C}$ assignment of two Pr spectra of the precipitated Cph1 $\Delta 2$ (Figure 1) is based on our previous DARR data from its frozen solution (Rohmer et al., 2008): preliminary assignment achieved by analysis of direct correlations between ${ }^{13} \mathrm{C}$ spins (red) and validated by indirect correlations originated from weak polarization transfers among isolated ${ }^{13} \mathrm{C}$ spins (purple). For example in the precipitated $\mathrm{Cph} 1 \Delta 2$, the previously unambiguous assignment for the propionate side-chains of two inner rings $B$ and $C$ in the frozen solution because of the signal overlapping of $\mathrm{C} 8 / \mathrm{C}^{1}$ and $\mathrm{C} 12 / \mathrm{C}^{1} 2^{1}$ (Rohmer et al., 2008) can be assigned unequivocally. Well-defined correlation networks of both propionates, C8 (144.2 ppm)-C8 ${ }^{1}$ (21.0 ppm)$\mathrm{C}^{2}(40.4 \mathrm{ppm})-\mathrm{C} 8^{3}(179.8 \mathrm{ppm})$ and $\mathrm{C} 12(144.9 \mathrm{ppm})-\mathrm{C} 12^{1}$ $(20.2 \mathrm{ppm})-\mathrm{C} 12^{2}(36.9 \mathrm{ppm})-\mathrm{C} 12^{3}(178.5 \mathrm{ppm})$ are apparent in the spectrum recorded with a mixing period of $2 \mathrm{~ms}$ (Figure 1, red). These assignments are confirmed by multi-bond correlation peaks involving non-propionate carbons such as $\mathrm{C} 7$ (125.2 ppm) $/ \mathrm{C}^{1}(8.7 \mathrm{ppm})-\mathrm{C} 8^{1} / \mathrm{C}^{2} / \mathrm{C}^{3}, \mathrm{C} 10(111.8 \mathrm{ppm}) / \mathrm{C} 11$ (126.5 ppm)-C12 ${ }^{1}, \mathrm{C} 13$ (126.2 ppm) $-\mathrm{C} 12^{1} / \mathrm{C} 12^{2} / \mathrm{C} 12^{3}$, and $\mathrm{C}_{13}{ }^{1}(10.7 \mathrm{ppm})-\mathrm{C} 12^{2} / \mathrm{C} 12^{3}$ resolved in the $28-\mathrm{ms}$ DARR mixing spectrum (Figure 1, purple). Intriguingly, for the $C$-ring propionate in the frozen solution state, two sets of chemical shifts were observed, indicative of local mobility of the chromophore and structural plasticity of the protein pocket (Song et al., 2011a), whereas only a single set was resolved for the precipitated Cph1 $\Delta 2$. Similarly, no signal splitting in this sample was observed for its bilin ring $A$ as a single correlation network for $\mathrm{C} 1$ (181. $5 \mathrm{ppm})-\mathrm{C} 2 \quad(35.8 \mathrm{ppm})-\left[\mathrm{C} 2^{1} \quad\right.$ (16.9 ppm) $]-\mathrm{C} 3$ (52.2 ppm)-[C3 $\left.{ }^{1}(46.1 \mathrm{ppm})-\mathrm{C} 3^{2}(20.9 \mathrm{ppm})\right]-\mathrm{C} 4$ (149.5 ppm). In general, the ${ }^{13} \mathrm{C}$ MAS spectrum is better resolved in the solution state in terms of relatively narrow spectral lines which

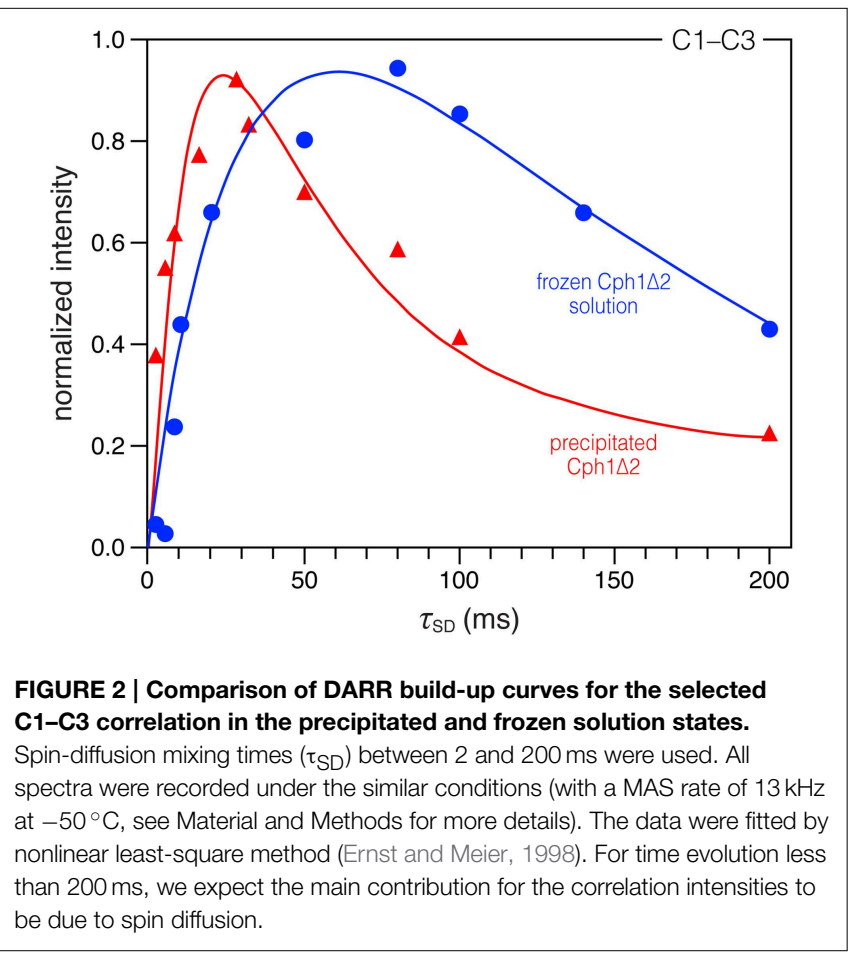

become broader on precipitation (see Figure 3 for comparison and discussed below).

The complete ${ }^{13} \mathrm{C}$ bilin assignment in the precipitated Cph1 $\Delta 2$ is summarized in Table $\mathrm{S} 1$, and the changes in its ${ }^{13} \mathrm{C}$ shifts $\left(\Delta \delta^{C}\right)$ upon precipitation is illustrated in Figure 4. The main features are as follows:

(i) Almost all the bilin signals move upfield, as represented by blue circles in Figure 4, amongst which most ${ }^{13} \mathrm{C}$ atoms $(27$ of 33) exhibit moderate shifts of $-0.5 \leq \Delta \delta^{\mathrm{C}} \leq-2.0 \mathrm{ppm}$ (Table S1). The global $\Delta \delta^{\mathrm{C}}$ induced by the partial dehydration reflect changes of the electronic structure of the bilin chromophore as well as the modification of its interactions with the protein surrounding. One might doubt whether the ${ }^{13} \mathrm{C}$ chemical shift scale has shifted between these two experiments. However, in addition to standard external referencing procedure (see Material and Methods),

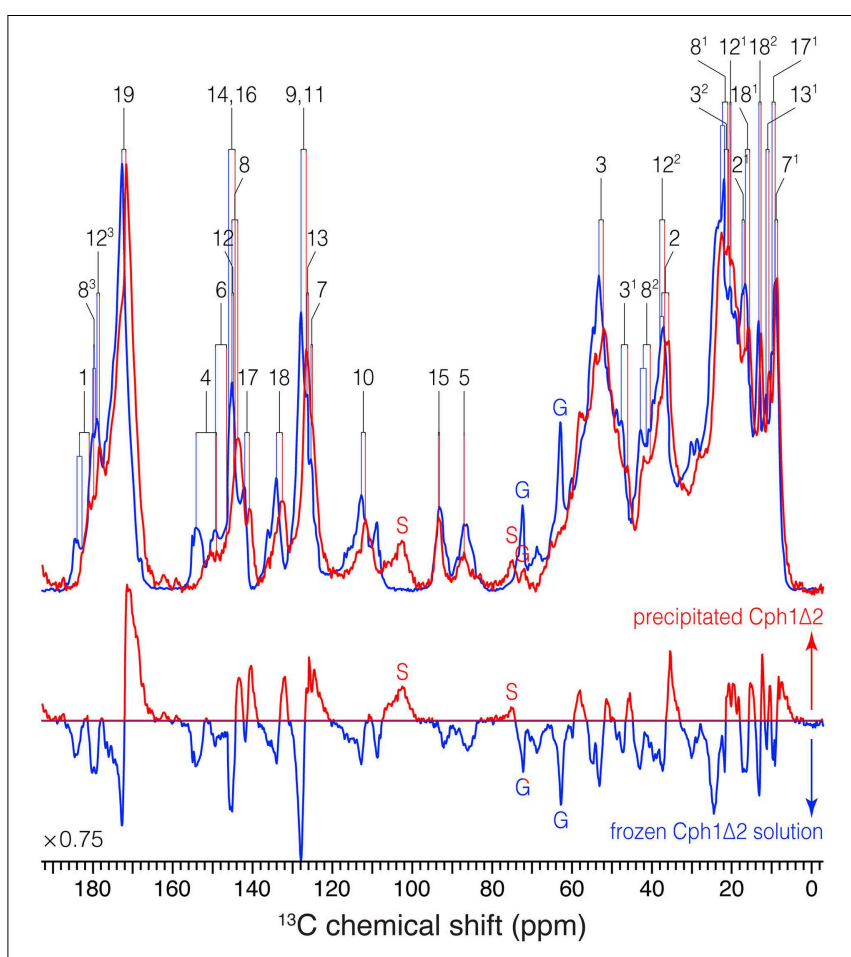

FIGURE 3 | 1D ${ }^{13} \mathrm{C}$ MAS spectra of $u-\left[{ }^{13} \mathrm{C},{ }^{15} \mathrm{~N}\right]-\mathrm{PCB}-\mathrm{Cph} 1 \Delta 2$ in the Pr state as an AmS pellet and as frozen solution. ${ }^{13} \mathrm{C}$ signals in the partial dehydrated (red) and frozen solution (blue) states are labeled. Signals of the natural abundance glycerol carbons at 62.8 and $72.1 \mathrm{ppm}$ (Williamson et al., 2001; Rosay et al., 2002; Rohmer et al., 2008) are labeled as "G". The spinning sidebands are labeled as "S". Normalized difference spectrum (bottom) was calculated as spectrum from the precipitated sample minus that of frozen solution. The MAS rate of both experiments was maintained at $13 \mathrm{kHz}$. Typical ${ }^{1} \mathrm{H} \pi / 2$ and ${ }^{13} \mathrm{C} \pi$ pulses were 3.0 and $5.2 \mu \mathrm{s}$, respectively. ${ }^{13} \mathrm{C}$ transverse magnetization created by the ramped $\mathrm{CP}$ was transformed from ${ }^{1} \mathrm{H}$ with a contact time of $2.048 \mu \mathrm{s}$ for both spectra. For ${ }^{1} \mathrm{H}$ decoupling, two-pulse phase modulation scheme with a pulse duration of $5.5-7 \mu \mathrm{s}$ and a ${ }^{1} \mathrm{H}$ r.f. field strength of $\sim 70 \mathrm{kHz}$ were employed. Both spectra were recorded with $8 \mathrm{k}$ scans with a recycle delay of $1.5 \mathrm{~s}$. A Lorentzian apodization function with line broadening factors of $20 \mathrm{~Hz}$ was applied to the data processing. 


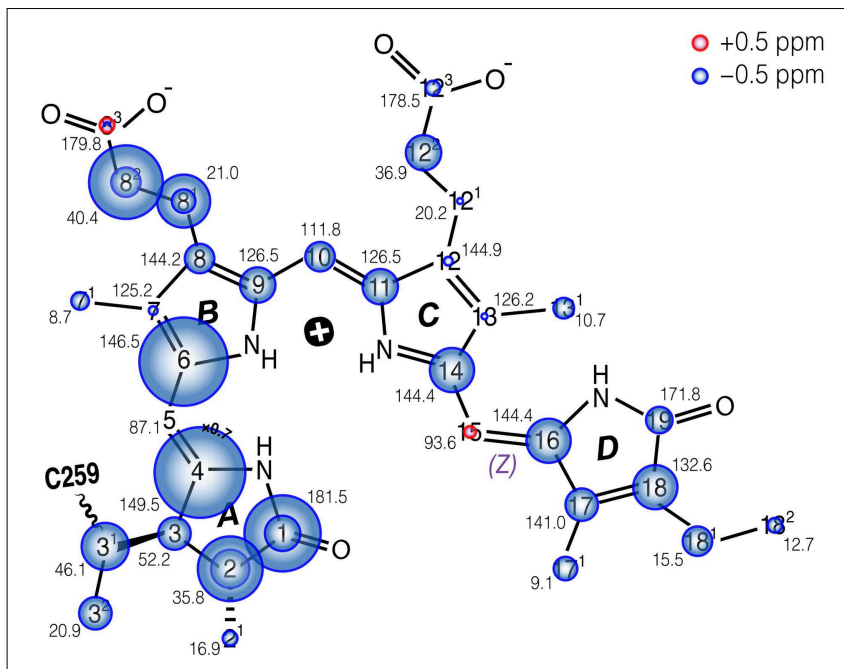

FIGURE 4 | Schematic of the changes in ${ }^{13} \mathrm{C}$ shifts of the $u-\left[{ }^{13} \mathrm{C},{ }^{15} \mathrm{~N}\right]-\mathrm{PCB}$ chromophore in $\mathrm{Cph1} \Delta 2$ in the Pr state as an AmS pellet and as frozen solution. The size of the circles is proportional to the ${ }_{\Delta \delta} \mathrm{C}$ as AmS precipitate minus frozen solution. Carbons showing doublings as frozen solution (Rohmer et al., 2008) are labeled with two circles. $\delta^{C}$ values of AmS precipitate as $\operatorname{Pr}$ are labeled by black numbers. $\delta^{\mathrm{C}}$ of both $\mathrm{Cph} 1 \Delta 2 \mathrm{Pr}$ samples are summarized in Table S1.

both ${ }^{13} \mathrm{C}$ MAS spectra show the same positions of glycerol natural abundance signal as internal standard (labeled as "G", Figure 3). Also, the precision of ${ }^{13} \mathrm{C}$ chemical shift measurement was controlled by comparing the spectra of frozen Cph $1 \Delta 2$ solution sample obtained before (shown in Figure 3, blue) and after (data not shown) a series of measurements of precipitated sample, only subtle variations of the ${ }^{13} \mathrm{C}$ chemical shifts were observed in the two spectra (before/after), and both are in line with the values reported $\left(\left|\Delta \delta^{\mathrm{C}}\right| \leq 0.2 \mathrm{ppm}\right.$ Rohmer et al., 2008). Hence, we conclude that the observed collective upfield shift is real and not an artifact that might have been occurred since wobbling of samples with high salt concentration is indeed difficult.

(ii) $\Delta \delta^{C}$ occurring in the region of pyrrole rings $A$ and $B$ are larger than those of rings $C$ and $D$, in which $C 4$ and C6 associated with the $A-B$ methine bridge experience the largest upfield shifts of -4.4 and $-3.0 \mathrm{ppm}$ respectively. This likely reflects some conformational change of ring $A$, e.g., a different $A$-ring orientation relative to the $B / C$-ring plane. Also, the robust ${ }^{13} \mathrm{C}$ shifts localized at bilin ring $A$ and the propionate side-chain of ring $B$ imply the modification of bilin-protein interactions because of a tight packing around rings $A-C$ seen in the structures of $C p h 1$ and plant phytochromes (Essen et al., 2008; Burgie et al., 2014).

(iii) The subtle shifts found at C9 and C11 $\left(\Delta \delta^{C}=-1.2 \mathrm{ppm}\right)$ strongly suggest the bilin ring system in the precipitated sample retains the protonation state (Rohmer et al., 2010b), i.e., all four bilin nitrogens are fully protonated and thus positively charged, as in the frozen solution sample as both Pr and Pfr (Rohmer et al., 2008). (iv) As can be seen from Figure 3, the ${ }^{13} \mathrm{C}$ line broadening of the bilin signals occurs when protein is precipitated (expressed as full-width at half maximum, $v_{1 / 2}$, summarized in Table S2). The broadening is most significant in the signals in/around $A$-ring region, for example, the ${ }^{13} \mathrm{C}$ linewidth of the ethylidene side-chain $\mathrm{C} 3^{1}$ increases from $342 \mathrm{~Hz}$ in the frozen solution to $489 \mathrm{~Hz}$ in the precipitated sample. A similar extent of line broadening is seen for $\mathrm{C} 4$ which broadens from $286 \mathrm{~Hz}$ (frozen solution) to $459 \mathrm{~Hz}$ (precipitate) and for C6 from 213 to $384 \mathrm{~Hz}$. Also, a number of signals from rings $C$ and $D$ broaden dramatically like C12, C17, and C18 (Table S2). The observed increase in ${ }^{13} \mathrm{C}$ linewidth upon precipitation does not result from the interference between ${ }^{1} \mathrm{H}$ decoupling and methyl group motion at low temperatures (Maus et al., 1996). For optimal decoupling performance in the case of Cph $1 \Delta 2$ precipitation, we scanned the ${ }^{1} \mathrm{H}$ r.f. field in a wide range at $-50{ }^{\circ} \mathrm{C}$, as for the spectra shown in Figure 3 (red). Also, the proton exchange with water molecules seems unlikely to be relevant for the observed ${ }^{13} \mathrm{C}$ line broadening which occurs not only in the positions close to hydrogen-bonding functions but spreads over the entire bilin chromophore (Table S2).

\section{Discussion}

\section{The Collective ${ }^{13} \mathrm{C}$ Upfield Shift of Bilin Carbons}

The most striking finding is the upfield shift of almost the entire bilin chromophore (as shown in Figure 4). This shift implies stronger shielding, most likely due to a reduced paramagnetic shift of the bilin carbons. Paramagnetic chemical shifts are related to the spatially-extended and non-spherical $\pi$-orbital structures of the ${ }^{13} \mathrm{C}$ nuclei. Decay of ${ }^{13} \mathrm{C}$ shifts can be related to a dense packing of the bilin chromophore in its binding pocket. This effect occurs in particular at rings $A$ and $B$, suggesting that the change of packing is especially pronounced in this region. For example, major bilin $\delta^{\mathrm{C}}$ changes are seen at $\mathrm{C} 1(-2.6 \mathrm{ppm})$, $\mathrm{C} 2(-2.2 \mathrm{ppm})$, and $\mathrm{C}^{1}(-1.6 \mathrm{ppm})$ associated with the ring $A$ (Figure 4). We suggest that these effects arise directly from a modification of the protein-chromophore linkage. Also, the C4 and C6 associated with the $A-B$ methine bridge exhibit striking upfield shifts ( -4.4 and $-3.0 \mathrm{ppm}$ respectively) on partial dehydration, reflecting a contortion of the thioether linkage which may also change the tilt of $\operatorname{ring} A$ in relation to the plane of rings $B$ and $C$. Such deviations may arise from proximity of electrostatic charges and steric effects due to the tighter packing. This interpretation is also supported by the observed increase of spin-diffusion efficiency upon precipitation.

In presence of concentrated AmS, the effective size of the protein molecule decreases, together with increased hydrophobic protein-protein interactions resulting in a higher packing density in the partial dehydrated state primarily for the surface groups, and a shortening of the internuclear distances compared to those in the frozen solution (Kachalova et al., 1991). The strength of dipolar couplings (e.g., between ${ }^{1} \mathrm{H}_{-}{ }^{1} \mathrm{H}$ and ${ }^{1} \mathrm{H}-{ }^{13} \mathrm{C}$ ) in this state is thus increased because it is proportional to the inverse cube of 
the distances between them (Huster et al., 2002; Reichert et al., 2004; Diakova et al., 2007). In this study, we observe that such difference in packing density between the partial dehydrated and frozen solution states affects not only surface groups but also the bilin and its hydrophobic binding pocket too.

A more compact protein environment of the bilin on precipitation is supported by the faster ${ }^{13} \mathrm{C}$ correlation buildup behavior observed in the DARR experiments. Taking C1C3 correlation (181.5/52.2 ppm Figure S1) as an example, a sharp maximum is reached at mixing time of $28 \mathrm{~ms}$ (build-up curve shown in Figure 2, red), whereas in the solution state this correlation continues to increase up to $80 \mathrm{~ms}$ (Figure 2, blue). The build-up curve for C1-C3 correlation in Figure 2 also reveals differences between the two states at short mixing times around $2 \mathrm{~ms}$. In the partially-dehydrated state (red), the correlation is already intense, whereas the correlation in the solution state (blue) is just above the $S / N$ level. Similar build-up behaviors are also seen for most correlations involving pyrrolic carbons: a maximum intensity is reached after a short mixing period of 8-32 ms (build-up curves not shown). The faster build-up rates observed in the precipitated state indicate a more efficient spin diffusion than in the frozen solution state, thus facilitating the cross-talk between protons. Also, local dynamics leads to a reduction of the spin-diffusion rates constants. For the Cph1 $\Delta 2$ precipitate, larger spin-diffusion rate constants can reasonably be expected because of the faster build-up behavior of the bilin correlations, suggesting a decrease in mobility within the bilinbinding pocket. Finally, although faster correlation build-up rates are observed in this sample, the maximum intensity reached is slightly smaller compared to the frozen solution (Figure 3). This could arise from relaxation effects and conformational transitions between different protein subconformations (energy minima), both of which are hydration-dependent (Zanotti et al., 1999; Krushelnitsky et al., 2009; Akbey et al., 2012). These data thus demonstrate that the process of partial dehydration causes changes of electronic structure of the bilin as well as its mobility within the pocket.

\section{An Increased Heterogeneous Bilin Environment}

The Pr ground-state heterogeneity is common in Pr-state phytochromes including both canonical Cph1 (Sineshchekov et al., 2002; Rohmer et al., 2008; Mroginski et al., 2009; Mailliet et al., 2011; Song et al., 2011a, 2012; Kim et al., 2014a) and oat phyA3 (Schmidt et al., 1998; Song et al., 2012) as well as bacteriophytochromes from Agrobacterium, D. radiodurans, and R. palustris (von Stetten et al., 2008; Wagner et al., 2008; Toh et al., 2010). A heterogeneous ground-state population was also noted for phytochrome-related CBCRs such as NpR6012g4 (Kim et al., 2012a,b,c; Rockwell et al., 2012; Chang et al., 2013). Our previous NMR study on frozen Cph1 $\Delta 2$ sample revealed the coexistence of two Pr isoforms in the solution, distinguished by their hydrogen-bonding networks and charge distribution patterns in the tetrapyrrole cavity (Song et al., 2011a). This idea has been extended by Kim et al. (2014a): they demonstrated using temperature-dependent pump-probe (PP) spectroscopy and singular-value decomposition (SVD) analysis that in solution the $\operatorname{Pr}$ subpopulations (fluorescent vs. photoactive) are in equilibrium at ambient temperatures and are associated with changes in the heat capacity $\left(C_{p}\right)$ of the protein.

For the precipitated Cph $1 \Delta 2$, however, the ${ }^{13} \mathrm{C}$ bilin signals are broader than those measured in frozen solution even for a number of peripheral carbons below $\sim 50 \mathrm{ppm}$ (Figure 3 and Table S2), suggesting a more heterogeneous protein environment of the bilin. Such a situation can arise from the amorphous character of the partial dehydrated sample (Kennedy and Bryant, 1990; Jia and Liu, 2006; Krushelnitsky et al., 2009), e.g., a broad distribution of protein subconformations with different interactions with the bilin (see below). The static disorder would be associated with the structural rearrangement of protein surface area because the addition of neutral salt like AmS constricts the hydration shells around the protein (Adamson and Gast, 1997) and thus results in increased hydrophobic protein-protein interactions. Although the possibility of structural distortions due to the formation of non-native electrostatic contacts between polar and charged groups in the partial dehydrated protein (Griebenow and Klibanov, 1995; Zanotti et al., 1999), the moderate ${ }^{13} \mathrm{C}$ shifts of $-0.5 \leq \Delta \delta^{\mathrm{C}} \leq-2.0 \mathrm{ppm}$ for most bilin carbons on partial dehydration (Table S1) would rule out major rearrangement of key protein-chromophore interactions. Moreover, water percolation through the protein interior is unlikely because buried water molecules are mainly strategically placed and tightly bound, and also because their population (of full hydration) is too low for them to form interconnected threads.

Intriguingly, $\mathrm{C} 4$ and $\mathrm{C} 6$ associated with the $A-B$ methine bridge show not only the largest ${ }^{13} \mathrm{C}$ chemical shift changes upon precipitation but also the greatest degree of line broadening (Tables S1,S2). A similar effect is also seen for other pyrrolic carbons associated with the ring $A$ and its linkage to the protein. These obvious differences of direct protein environment of the ring $A$ might reflect also changes of the water networks around the ring. Hence, under precipitation, the protein becomes more densely packed and its structural order is partially lost. These changes affect in particular rings $A$ and $B$, here in addition also a conformational change of the chromophore, probably a change of the dihedral angle about the $\mathrm{C} 4=\mathrm{C} 5$ bond occurs. Since the less affected rings $C$ and $D$ are more hidden in the protein interior, i.e., the ring $D$ is completely shielded from the solvent by the side-chains of several residues of the GAF domain and the tongue region (Essen et al., 2008), it is reasonable to assume that changes in the water environment, caused by the partial dehydration, are responsible for these changes. It appears that the lack of nearby water molecules do not modify photoprocess affects between rings $C$ and $D$ but rather result in a fixation of the conformations. That implies that a fully-hydrated protein does not have a single conformation but a range of conformations which appear to be averaged on NMR timescale. Water may act as "lubricant" in protein conformational changes. As the sample is precipitated, less free water molecules are available, so the ordered protein conformation collapses, and thus protein molecules in different subconformations become trapped. It has been proposed from the Cph1 $\Delta 2$ Pr crystal structure (PDB code 2VEA) that the bilin is sealed off from the solvent (Essen et al., 2008), although the higher-resolution structure of the Y263F 
mutant (PDB code 2ZQ5) implies that the seal is far from perfect (Mailliet et al., 2011). Future MAS NMR experiments might reveal which water molecules in the tetrapyrrole cavity (especially those in close contacts with the ring $A$ ) are affected in the process of partial dehydration, allowing their functional role in the reaction dynamics to be understood. It is evident from our MAS data that $\mathrm{Cph} 1 \Delta 2$ precipitate as $\operatorname{Pr}$ shows increased heterogeneity of bilin environment.

\section{Conclusion}

AmS precipitation is a mild, reversibly treatment commonly used to purify and concentrate proteins. It acts by withdrawing water from the hydration shell surrounding proteins, thereby reducing their solubility. The precipitate is quite dense and can be compacted by centrifugation, thereby offering a potential new route to gaining 3D structural information via solidstate NMR which otherwise requires highly-concentrated frozen samples. On the other hand, AmS precipitation might have more extensive effects, blocking access to the native structure. Here we have investigated the structure of AmS-precipitated holo-Cph1 $\Delta 2$ in vitro assembled with $u-\left[{ }^{13} \mathrm{C},{ }^{15} \mathrm{~N}\right]-\mathrm{PCB}$ in its Pr state using solid-state NMR. This represents a useful case study as earlier studies showed that not only is the phytochrome photochromic state unaffected by AmS precipitation, resonance Raman spectra differ only slightly between AmS precipitates and frozen solutions (Matysik et al., 1995). We have extensively studied frozen solutions of $\mathrm{Cph} 1 \Delta 2$ phytochrome using solidstate NMR, thus we are in a good position to assay possible effects of the AmS technique with Cph1 $\Delta 2$. Indeed, the bilin ${ }^{13} \mathrm{C}$ lines are broadened in the precipitated state, probably as a result of a

\section{References}

Adamson, A. W., and Gast, A. P. (1997). Physical Chemistry of Surfaces 4th Edn. New York, NY: John Wiley.

Akbey, Ü., van Rossum, B.-J., and Oschkinat, B.-J. (2012). Practical aspects of high-sensitivity multidimensional ${ }^{13} \mathrm{C}$ MAS NMR spectroscopy of perdeuterated proteins. J. Magn. Reson. 217, 77-85. doi: 10.1016/j.jmr.2012. 02.015

Auldridge, M. E., and Forest, K. T. (2011). Bacterial phytochromes: more than meets the light. Crit. Rev. Biochem. Mol. Biol. 46, 67-88. doi: 10.3109/10409238.2010.546389

Bennett, A. E., Rienstra, C. M., Auger, M., Lakshmi, K. V., and Griffin, R. G. (1995). Heteronuclear decoupling in rotating solids. J. Chem. Phys. 103, 6951-6958. doi: $10.1063 / 1.470372$

Bhoo, S. H., Davis, S. J., Walker, J., Karniol, B., and Vierstra, R. D. (2001). Bacteriophytochromes are photochromic histidine kinases using a biliverdin chromophore. Nature 414, 776-779. doi: 10.1038/414776a

Borthwick, H. A., Hendricks, S. B., Parker, M. W., Toole, E. H., and Toole, V. K. (1952). A reversible photoreaction controlling seed germination. Proc. Natl. Acad. Sci. U.S.A. 38, 662-666. doi: 10.1073/pnas.38.8.662

Burgie, E. S., Bussell, A. N., Walker, J. M., Dubiel, K., and Vierstra, R. D. (2014). Crystal structure of the photosensing module from a red/far-red lightabsorbing plant phytochrome. Proc. Natl. Acad. Sci. U.S.A. 111, 10179-10184. doi: 10.1073/pnas.1403096111

Chang, C.-W., Gottlieb, S. M., Kim, P. W., Rockwell, N. C., Lagarias, J. C., and Larsen, D. S. (2013). Reactive ground-state pathways are not ubiquitous in red/green cyanobacteriochromes. J. Phys. Chem. B 117, 11229-11238. doi: $10.1021 / j p 402112 u$ more heterogeneous bilin environment. We identify a significant collective upfield ${ }^{13} \mathrm{C}$ chemical shift of the bilin compared to the ${ }^{13} \mathrm{C}$ data obtained from the frozen solution which reflect more dense sample packing around the bilin chromophore likely caused by the partial dehydration. Additionally, the MAS data reveal a dehydration-induced conformational change of the bilin chromophore, in particular for rings $A$ and $B$. However, other key factors capable of modulating light absorption like protonation of the bilin and its direct hydrogen-bonding network seem to be unaffected by AmS precipitation. We conclude, therefore, that $\mathrm{AmS}$ precipitation can have significant effects throughout the protein and thus that the method, while perhaps useful in specific cases, might not provide bona fide structure/functional information. On the other hand, this method might allow for obtaining information on the local water pool and its exchange to the bulk. Future studies with AmS (or other salts) might elucidate how the salt-related dehydration process affects protein structure.

\section{Acknowledgments}

This work was supported by Deutsche Forschungsgemeinschaft (DFG) grant $\mathrm{Hu} 702 / 8$ and Nederlandse Organisatie voor Wetenschappelijk Onderzoek (NWO) grants DN 89-190 and ALW 822.02.007.

\section{Supplementary Material}

The Supplementary Material for this article can be found online at: http://journal.frontiersin.org/article/10.3389/fmolb. 2015.00042

Chen, Y., Zhang, J., Luo, J., Tu, J. M., Zeng, X. L., Xie, J., et al. (2012). Photophysical diversity of two novel cyanobacteriochromes with phycocyanobilin chromophores: photochemistry and dark reversion kinetics. FEBS J. 279, 40-54. doi: 10.1111/j.1742-4658.2011.08397.x

Dasgupta, J., Frontiera, R. R., Taylor, K. C., Lagarias, J. C., and Mathies, R. A. (2009). Ultrafast excited-state isomerization in phytochrome revealed by femtosecond stimulated Raman spectroscopy. Proc. Natl. Acad. Sci. U.S.A. 106, 1784-1789. doi: 10.1073/pnas.0812056106

Davis, S. J., Vener, A. V., and Vierstra, R. D. (1999). Bacteriophytochromes: phytochrome-like photoreceptors from nonphotosynthetic eubacteria. Science 286, 2517-2520. doi: 10.1126/science.286.5449.2517

De Riso, V., Raniello, R., Maumus, F., Rogato, A., Bowler, C., and Falciatore, A. (2009). Gene silencing in the marine diatom Phaeodactylum tricornutum. Nucleic Acids Res. 37:e96. doi: 10.1093/nar/gkp448

Diakova, G., Goddard, Y. A., Korb, J.-P., and Bryant, R. G. (2007). Changes in protein structure and dynamics as a function of hydration from ${ }^{1} \mathrm{H}$ second moments. J. Magn. Reson. 189, 166-172. doi: 10.1016/j.jmr.2007.09.005

Ernst, M., and Meier, B. H. (1998). "Spin diffusion in solids," in Solid State NMR of Polymers, eds I. Ando and T. Asakura (Amsterdam: Elsevier), 83-121. doi: 10.1016/S0167-6881(98)80007-4

Essen, L.-O., Mailliet, J., and Hughes, J. (2008). The structure of a complete phytochrome sensory module in the Pr ground state. Proc. Natl. Acad. Sci. U.S.A. 105, 14709-14714. doi: 10.1073/pnas.0806477105

Fischer, A. J., and Lagarias, J. C. (2004). Harnessing phytochrome's glowing potential. Proc. Natl. Acad. Sci. U.S.A. 101, 17334-17339. doi: 10.1073/pnas.0407645101

Franklin, K. A., and Quail, P. H. (2010). Phytochrome functions in Arabidopsis development. J. Exp. Bot. 61, 11-24. doi: 10.1093/jxb/erp304 
Froehlich, A. C., Noh, B., Vierstra, R. D., Loros, J., and Dunlap, J. C. (2005). Genetic and molecular analysis of phytochromes from the filamentous fungus Neurospora crassa. Eukaryot. Cell 4, 2140-2152. doi: 10.1128/EC.4.12.21402152.2005

Giraud, E., Fardoux, J., Fourrier, N., Hannibal, L., Genty, B., Bouyer, P., et al. (2002). Bacteriophytochrome controls photosystem synthesis in anoxygenic bacteria. Nature 417, 202-205. doi: 10.1038/417202a

Goddard, T. D., and Kneller, D. G. (2008). SPARKY, Version 3. San Francisco, CA: University of California.

Griebenow, K., and Klibanov, A. M. (1995). Lyophilization-induced reversible changes in the secondary structure of proteins. Proc. Natl. Acad. Sci. U.S.A. 92, 10969-10976. doi: 10.1073/pnas.92.24.10969

Hahn, J., Strauss, H. M., Landgraf, F. T., Gimenèz, H. F., Lochnit, G., Schmieder, P., et al. (2006). Probing protein-chromophore interactions in Cph1 phytochrome by mutagenesis. FEBS J. 273, 1415-1429. doi: 10.1111/j.1742-4658.2006.05164.x

Hahn, J., Strauss, H. M., and Schmieder, P. (2008). Heteronuclear NMR investigation on the structure and dynamics of the chromophore binding pocket of the cyanobacterial phytochrome Cph1. J. Am. Chem. Soc. 130, 11170-11178. doi: 10.1021/ja8031086

Hirose, Y., Rockwell, N. C., Nishiyama, K., Narikawa, R., Ukaji, Y., Inomata, K., et al. (2013). Green/red cyanobacteriochromes regulate complementary chromatic acclimation via a protochromic photocycle. Proc. Natl. Acad. Sci. U.S.A. 110, 4974-4979. doi: 10.1073/pnas.1302909110

Hughes, J. (2010). Phytochrome three-dimensional structures and functions. Biochem. Soc. Trans. 38, 710-716. doi: 10.1042/BST0380710

Hughes, J., Lamparter, T., Mittmann, F., Hartmann, E., Gärtner, W., Wilde, A., et al. (1997). A prokaryotic phytochrome. Nature 386, 663. doi: 10.1038/386663a0

Huster, D., Yao, X., and Hong, M. (2002). Membrane protein topology probed by ${ }^{1} \mathrm{H}$ spin diffusion from lipids using solid-state NMR spectroscopy. J. Am. Chem. Soc. 124, 874-883. doi: 10.1021/ja017001r

Jia, Y., and Liu, X.-Y. (2006). From surface self-assembly to crystallization: prediction of protein crystallization conditions. J. Phys. Chem. B 110, 6949-6955. doi: 10.1021/jp0536089

Kachalova, G. S., Morozov, V. N., Morozova, T. Y., Myachin, E. T., Vagin, A. A., Strokopytov, B. V., et al. (1991). Comparison of structures of dry and wet hen egg-white lysozyme molecule at $1.8 \AA$ resolution. FEBS Lett. 284, 91-94. doi: 10.1016/0014-5793(91)80769-Y

Kehoe, D. M., and Grossman, A. R. (1996). Similarity of a chromatic adaptation sensor to phytochrome and ethylene receptors. Science 273, 1409-1412. doi: 10.1126/science.273.5280.1409

Kennedy, S. D., and Bryant, R. G. (1990). Structural effects of hydration: studies of lysozyme by ${ }^{13} \mathrm{C}$ solids NMR. Biopolymers 29, 1801-1806. doi: 10.1002/bip.360291411

Kim, P. W., Freer, L. H., Rockwell, N. C., Martin, S. S., Lagarias, J. C., and Larsen, D. S. (2012a). Second-chance initiation dynamics of the cyanobacterial photocycle in the NpR6012 GAF4 domain of Nostoc punctiforme. J. Am. Chem. Soc. 134, 130-133. doi: 10.1021/ja209533x

Kim, P. W., Freer, L. H., Rockwell, N. C., Martin, S. S., Lagarias, J. C., and Larsen, D. S. (2012b). Femtosecond photodynamics of the red/green cyanobacteriochrome NpR6012g4 from Nostoc punctiforme. 1. Forward dynamics. Biochemistry 51, 608-618. doi: 10.1021/bi201507k

Kim, P. W., Freer, L. H., Rockwell, N. C., Martin, S. S., Lagarias, J. C., and Larsen, D. S. (2012c). Femtosecond photodynamics of the red/green cyanobacteriochrome NpR6012g4 from Nostoc punctiforme. 2. Reverse dynamics. Biochemistry 51, 619-630. doi: 10.1021/bi2017365

Kim, P. W., Rockwell, N. C., Freer, L. H., Chang, C.-W., Martin, S. S., Lagarias, J. C., et al. (2013). Unraveling the primary isomerization dynamics in cyanobacterial phytochrome Cph1 with multipulse manipulations. J. Phys. Chem. Lett. 4, 2605-2609. doi: 10.1021/jz401443q

Kim, P. W., Rockwell, N. C., Martin, S. S., Lagarias, J. C., and Larsen, D. S. (2014a). Dynamic inhomogeneity in the photodynamics of cyanobacterial phytochrome Cph1. Biochemistry 53, 2818-2826. doi: 10.1021/bi500108s

Kim, P. W., Rockwell, N. C., Martin, S. S., Lagarias, J. C., and Larsen, D. S. (2014b). Heterogeneous photodynamics of the $\mathrm{P}_{\mathrm{fr}}$ state in the cyanobacterial phytochrome Cph1. Biochemistry 53, 4601-4611. doi: 10.1021/ bi5005359

Krushelnitsky, A., Zinkevich, T., Mukhametshina, N., Tarasova, N., Gogolev, Y., Gnezdilov, O., et al. (2009). ${ }^{13} \mathrm{C}$ and ${ }^{15} \mathrm{~N}$ NMR study of the hydration response of T4 lysozyme and $\alpha \mathrm{B}$-crystallin internal dynamics. J. Phys. Chem. B 113, 10022-10034. doi: 10.1021/jp900337x

Lamparter, T., Mittmann, F., Gärtner, W., Börner, T., Hartmann, E., and Hughes, J. (1997). Characterization of recombinant phytochrome from the cyanobacterium Synechocystis. Proc. Natl. Acad. Sci. U.S.A. 94, 11792-11797. doi: 10.1073/pnas.94.22.11792

Lee, J. M., Lee, J., Kim, T., and Lee, S. K. (2013). Switchable gene expression in Escherichia coli using a miniaturized photobioreactor. PLoS ONE 8:e52382. doi: 10.1371/journal.pone.0052382

Levskaya, A., Chevalier, A. A., Tabor, J. J., Simpson, Z. B., Lavery, L. A., Levy, M., et al. (2005). Synthetic biology: engineering Escherichia coli to see light. Nature 438, 441-442. doi: 10.1038/nature04405

Levskaya, A., Weiner, O. D., Lim, W. A., and Voigt, C. A. (2009). Spatiotemporal control of cell signalling using a light-switchable protein interaction. Nature 461, 997-1001. doi: 10.1038/nature08446

Mailliet, J., Psakis, G., Schroeder, C., Kaltofen, S., Dürrwang, U., Hughes, J., et al. (2009). Dwelling in the dark: procedures for the crystallography of phytochromes and other photochromic proteins. Acta Cryst. D65, 1232-1235. doi: 10.1107/S0907444909034106

Mailliet, J., Psakis, G., Sineshchekov, V., Essen, L.-O., and Hughes, J. (2011). Spectroscopy and a high-resolution crystal structure of Tyr-263 mutant of cyanobacterial phytochrome Cph1. J. Mol. Biol. 413, 115-127. doi: 10.1016/j.jmb.2011.08.023

Mateos, J. L., Luppi, J. B., Ogorodnikova, O. B., Sineshchekov, A. A., Yanovsky, M. J., and Braslavsky, S. E. (2006). Functional and biochemical analysis of the N-terminal domain of phytochrome A. J. Biol. Chem. 281, 34421-34429. doi: 10.1074/jbc.M603538200

Matsushita, T., Mochizuki, N., and Nagatani, A. (2003). Dimers of the N-terminal domain of phytochrome B are functional in the nucleus. Nature 424, 571-574. doi: $10.1038 /$ nature 01837

Matysik, J., Hildebrandt, P., Schlamann, W., Braslavsky, S. E., and Schaffner, K. (1995). Fourier-transform resonance Raman spectroscopy of intermediates of the phytochrome photocycle. Biochemistry 34, 10497-10507. doi: 10.1021/bi00033a023

Maus, D. C., Copié, V., Sun, B., Griffiths, J. M., Griffin, R. G., Luo, S., et al. (1996). A solid-state NMR study of tungsten methyl group dynamics in [W( $\eta^{5}$ $\left.\left.\mathrm{C}_{5} \mathrm{Me}_{5}\right) \mathrm{Me}_{4}\right]\left[\mathrm{PF}_{6}\right]$. J. Am. Chem. Soc. 118, 5665-5671. doi: 10.1021/ja960248h

Möglich, A., and Moffat, K. (2010). Engineered photoreceptors as novel optogenetic tools. Photochem. Photobiol. Sci. 9, 1286-1300. doi: 10.1039/c0pp00167h

Mroginski, M. A., von Stetten, D., Velazquez Escobar, F., Strauss, H. M., Kaminski, S., Scheerer, P., et al. (2009). Chromophore structure of cyanobacterial phytochrome Cph1 in the Pr state: reconciling structural and spectroscopic data by QM/MM calculations. Biophys. J. 96, 4153-4163. doi: 10.1016/j.bpj.2009.02.029

Müller, K., Engesser, R., Schulz, S., Steinberg, T., Tomakidi, P., Weber, C. C., et al. (2013). Multi-chromatic control of mammalian gene expression and signalling. Nucleic Acids Res. 41, e124. doi: 10.1093/nar/gkt340

Müller, K., Engesser, R., Timmer, J., Zurbriggen, M. D., and Weber, W. (2014b). Orthogonal optogenetic triple-gene control in mammalian cells. ACS Synth. Biol. 3, 796-801. doi: 10.1021/sb500305v

Müller, K., and Weber, W. (2013). Optogenetic tools for mammalian systems. Mol. BioSyst. 9, 596-608. doi: 10.1039/c3mb25590e

Müller, K., Zurbriggen, M. D., and Weber, W. (2014a). Control of gene expression using a red- and far-red light-responsive bi-stable toggle switch. Nat. Protoc. 9, 622-632. doi: 10.1038/nprot.2014.038

Nagatani, A. (2010). Phytochrome: structural basis for its functions. Curr. Opin. Plant Biol. 13, 565-570. doi: 10.1016/j.pbi.2010.07.002

Narikawa, R., Ishizuka, T., Muraki, N., Shiba, T., Kurisu, G., and Ikeuchi, M. (2013). Structures of cyanobacteriochromes from phototaxis regulators AnPixJ and TePixJ reveal general and specific photoconversion mechanism. Proc. Natl. Acad. Sci. U.S.A. 110, 918-923. doi: 10.1073/pnas.1212098110

Piatkevich, K. D., Subach, F. V., and Verkhusha, V. V. (2013). Engineering of bacterial phytochromes for near-infrared imaging, sensing, and light-control in mammals. Chem. Soc. Rev. 42, 3441-3452. doi: 10.1039/c3cs35458j

Psakis, G., Mailliet, J., Lang, C., Teufel, L., Essen, L.-O., and Hughes, J. (2011). Signaling kinetics of cyanobacterial phytochrome Cph1, a light regulated histidine kinase. Biochemistry 50, 6178-6188. doi: 10.1021/bi200612d 
Reichert, D., Pascui, O., deAzevedo, E. R., Bonagamba, T. J., Arnold, K., and Huster, D. (2004). A solid-state NMR study of the fast and slow dynamics of collagen fibrils at varying hydration levels. Magn. Reson. Chem. 42, 276-284. doi: $10.1002 / \mathrm{mrc} .1334$

Rockwell, N. C., Duanmu, D., Martin, S. S., Bachy, C., Price, D. C., Bhattacharya, D., et al. (2014b). Eukaryotic algal phytochromes span the visible spectrum. Proc. Natl. Acad. Sci. U.S.A. 111, 3871-3876. doi: 10.1073/pnas.1401871111

Rockwell, N. C., and Lagarias, J. C. (2010). A brief history of phytochromes. Chemphyschem 11, 1172-1180. doi: 10.1002/cphc.200900894

Rockwell, N. C., Martin, S. S., Feoktistova, K., and Lagarias, J. C. (2011). Diverse two-cysteine photocycles in phytochromes and cyanobacteriochromes. Proc. Natl. Acad. Sci. U.S.A. 108, 11854-11859. doi: 10.1073/pnas.1107844108

Rockwell, N. C., Martin, S. S., Gulevich, A. G., and Lagarias, J. C. (2014a). Conserved phenylalanine residues are required for blue-shifting of cyanobacteriochrome photoproducts. Biochemistry 53, 3118-3130. doi: 10.1021/bi500037a

Rockwell, N. C., Martin, S. S., and Lagarias, J. C. (2012). Red/green cyanobacteriochromes: sensors of color and power. Biochemistry 51, 9667-9677. doi: 10.1021/bi3013565

Rockwell, N. C., Shang, L., Martin, S. S., and Lagarias, J. C. (2009). Distinct classes of red/far-red photochemistry within the phytochrome superfamily. Proc. Natl. Acad. Sci. U.S.A. 106, 6123-6127. doi: 10.1073/pnas.0902370106

Rockwell, N. C., Su, Y.-S., and Lagarias, J. C. (2006). Phytochrome structure and signaling mechanisms. Annu. Rev. Plant Biol. 57, 837-858. doi: 10.1146/annurev.arplant.56.032604.144208

Rohmer, T., Lang, C., Bongards, C., Gupta, K. B., Neugebauer, J., Hughes, J., et al. (2010a). Phytochrome as molecular machine: revealing chromophore action during the $\mathrm{Pfr} \rightarrow \operatorname{Pr}$ photoconversion by magic-angle spinning NMR spectroscopy. J. Am. Chem. Soc. 132, 4431-4437. doi: 10.1021/ ja9108616

Rohmer, T., Lang, C., Gärtner, W., Hughes, J., and Matysik, J. (2010b). Role of the protein cavity in phytochrome chromoprotein assembly and double-bond isomerization: a comparison with model compounds. Photochem. Photobiol. 86, 856-861. doi: 10.1111/j.1751-1097.2010.00740.x

Rohmer, T., Lang, C., Hughes, J., Essen, L.-O., Gärtner, W., and Matysik, J. (2008). Light-induced chromophore activity and signal transduction in phytochromes observed by ${ }^{13} \mathrm{C}$ and ${ }^{15} \mathrm{~N}$ magic-angle spinning NMR. Proc. Natl. Acad. Sci. U.S.A. 105, 15229-15234. doi: 10.1073/pnas.0805696105

Rohmer, T., Strauss, H., Hughes, J., de Groot, H., Gärtner, W., Schmieder, P., et al. (2006). ${ }^{15} \mathrm{~N}$ MAS NMR studies of Cph1 phytochrome: chromophore dynamics and intramolecular signal transduction. J. Phys. Chem. B 110, 20580-20585. doi: $10.1021 /$ jp062454+

Rosay, M., Weis, V., Kreischer, K. E., Temkin, R. J., and Griffin, R. G. (2002). Two-dimensional ${ }^{13} \mathrm{C}-{ }^{13} \mathrm{C}$ correlation spectroscopy with magic angle spinning and dynamic nuclear polarization. J. Am. Chem. Soc. 124, 3214-3215. doi: 10.1021/ja0176752

Scheerer, P., Michael, N., Park, J. H., Nagano, S., Choe, H.-W., Inomata, K., et al. (2010). Light-induced conformational changes of the chromophore and the protein in phytochromes: bacterial phytochromes as model systems. Chemphyschem 11, 1090-1105. doi: 10.1002/cphc.200900913

Schmidt, P., Gensch, T., Remberg, A., Gärtner, W., Braslavsky, S. E., and Schaffner, K. (1998). The complexity of the $P_{r}$ to $P_{f r}$ phototransformation kinetics is an intrinsic property of native phytochrome. Photochem. Photobiol. 68, 754-761.

Shimizu-Sato, S., Huq, E., Tepperman, J. M., and Quail, P. H. (2002). A light-switchable gene promoter system. Nat. Biotechnol. 20, 1041-1044. doi: $10.1038 /$ nbt734

Shu, X., Royant, A., Lin, M. Z., Aguilera, T. A., Lev-Ram, V., Steinbach, P. A., et al. (2009). Mammalian expression of infrared fluorescent proteins engineered from a bacterial phytochrome Science 324, 804-807. doi: $10.1126 /$ science. 1168683

Sineshchekov, V., Koppel, L., Esteban, B., Hughes, J., and Lamparter, T. (2002). Fluorescence investigation of the recombinant cyanobacterial phytochrome (Cph1) and its C-terminally truncated monomeric species (Cph1 $\Delta 2)$ : implication for holoprotein assembly, chromophore-apoprotein interaction and photochemistry. J. Photochem. Photobiol. B 67, 39-50. doi: 10.1016/S10111344(02)00282-8

Song, C., Essen, L.-O., Gärtner, W., Hughes, J., and Matysik, J. (2012). Solidstate NMR spectroscopic study of chromophore-protein interactions in the
Pr ground state of plant phytochrome A. Mol. Plant. 5, 698-715. doi: $10.1093 / \mathrm{mp} / \mathrm{sss} 017$

Song, C., Psakis, G., Kopycki, J., Lang, C., Matysik, J., and Hughes, J. (2014). The D-ring, not the A-ring, rotates in Synechococcus OS-B' phytochrome. J. Biol. Chem. 289, 2552-2562. doi: 10.1074/jbc.M113.520031

Song, C., Psakis, G., Lang, C., Mailliet, J., Gärtner, W., Hughes, J., et al. (2011a). Two ground state isoforms and a chromophore D-ring photoflip triggering extensive intramolecular changes in a canonical phytochrome. Proc. Natl. Acad. Sci. U.S.A. 108, 3842-3847. doi: 10.1073/pnas.1013377108

Song, C., Psakis, G., Lang, C., Mailliet, J., Zaanen, J., Gärtner, W., et al. (2011b). On the collective nature of phytochrome photoactivation. Biochemistry 50, 10987-10989. doi: 10.1021/bi201504a

Strauss, H. M., Hughes, J., and Schmieder, P. (2005a). Heteronuclear solutionstate NMR studies of the chromophore in cyanobacterial phytochrome Cph1. Biochemistry 44, 8244-8250. doi: 10.1021/bi050457r

Strauss, H. M., Schmieder, P., and Hughes, J. (2005b). Light-dependent dimerisation in the N-terminal sensory module of cyanobacterial phytochrome 1. FEBS Lett. 579, 3970-3974. doi: 10.1016/j.febslet.2005.06.025

Tabor, J. J., Salis, H., Simpson, Z. B., Chevalier, A. A., Levskaya, A., Marcotte, E. M., et al. (2009). A synthetic genetic edge detection program. Cell 137, 1272-1281. doi: 10.1016/j.cell.2009.04.048

Takala, H., Björling, A., Berntsson, O., Lehtivuori, H., Niebling, S., Hoernke, M., et al. (2014). Signal amplification and transduction in phytochrome photosensors. Nature 509, 245-248. doi: 10.1038/nature13310

Takegoshi, K., Nakamura, S., and Terao, T. (2001). ${ }^{13} \mathrm{C}-{ }^{1} \mathrm{H}$ dipolar-assisted rotational resonance in magic-angle spinning NMR. Chem. Phys. Lett. 344, 631-637. doi: 10.1016/S0009-2614(01)00791-6

Tischer, D., and Weiner, O. D. (2014). Illuminating cell signalling with optogenetic tools. Nat. Rev. Mol. Cell Biol. 15, 551-558. doi: 10.1038/nrm3837

Toh, K. C., Stojković, E. A., van Stokkum, I. H. M., Moffat, K., and Kennis, J. T. M. (2010). Proton-transfer and hydrogen-bond interactions determine fluorescence quantum yield and photochemical efficiency of bacteriophytochrome. Proc. Natl. Acad. Sci. U.S.A. 107, 9170-9175. doi: 10.1073/pnas.0911535107

van Thor, J. J., Borucki, B., Crielaard, W., Otto, H., Lamparter, T., Hughes, J., et al. (2001). Light-induced proton release and proton uptake reactions in the cyanobacterial phytochrome Cph1. Biochemistry 40, 11460-11471. doi: 10.1021/bi002651d

van Thor, J. J., Fisher, N., and Rich, P. R. (2005). Assignments of the Pfr-Pr FTIR difference spectrum of cyanobacterial phytochrome Cph1 using ${ }^{15} \mathrm{~N}$ and ${ }^{13} \mathrm{C}$ isotopically labeled phycocyanobilin chromophore. J. Phys. Chem. B 109, 20597-20604. doi: 10.1021/jp052323t

van Thor, J. J., Mackeen, M., Kuprov, I., Dwek, R. A., and Wormald, M. R. (2006). Chromophore structure in the photocycle of the cyanobacterial phytochrome Cph1. Biophys. J. 91, 1811-1822. doi: 10.1529/biophysj.106.084335

Velazquez Escobar, F., von Stetten, D., Günther-Lütkens, M., Keidel, A., Michael, N., Lamparter, T., et al. (2015). Conformational heterogeneity of the Pfr chromophore in plant and cyanobacterial phytochromes. Front. Mol. Biosci. 2:37. doi: $10.3389 /$ fmolb.2015.00037

von Stetten, D., Günther, M., Scheerer, P., Murgida, D. H., Mroginski, M. A., Krauss, N., et al. (2008). Chromophore heterogeneity and photoconversion in phytochrome crystals and solution studied by resonance Raman spectroscopy. Angew. Chem. Int. Ed. Engl. 47, 4753-4755. doi: 10.1002/anie.200 705716

Wagner, J. R., Brunzelle, J. S., Forest, K. T., and Vierstra, R. D. (2005). A lightsensing knot revealed by the structure of the chromophore-binding domain of phytochrome. Nature 438, 325-331. doi: 10.1038/nature04118

Wagner, J. R., Zhang, J., von Stetten, D., Günther, M., Murgida, D. H., Mroginski, M. A., et al. (2008). Mutational analysis of Deinococcus radiodurans bacteriophytochrome reveals key amino acids necessary for the phytochromicity and proton exchange cycle of phytochromes. J. Biol. Chem. 283, 12212-12226. doi: 10.1074/jbc.M709355200

Williamson, P. T. F., Bains, S., Chung, C., Cooke, R., Meier, B. H., and Watts, A. (2001). "Characterization and assignment of uniformly labeled NT(8-13) at the agonist binding site of the G-protein coupled neurotensin receptor," in Perspectives on Solid State NMR in Biology, eds S. R. Kiihne and H. J. M. de Groot (Dordrecht: Kluwer Academic Publishers), 191-202. doi: 10.1007/97894-017-2579-8_17 
Yang, X., Kuk, J., and Moffat, K. (2009). Conformational differences between the Pfr and Pr states in Pseudomonas aeruginosa bacteriophytochrome. Proc. Natl. Acad. Sci. U.S.A. 106, 15639-15644. doi: 10.1073/pnas.0902178106

Yang, X., Kuk, J., and Moffat, K. (2008). Crystal structure of Pseudomonas aeruginosa bacteriophytochrome: photoconversion and signal transduction. Proc. Natl. Acad. Sci. U.S.A. 105, 14715-14720. doi: 10.1073/pnas.0806718105

Yang, X., Ren, Z., Kuk, K., and Moffat, K. (2011). Temperature-scan cryocrystallography reveals reaction intermediates in bacteriophytochrome. Nature 479, 428-432. doi: 10.1038/nature10506

Yang, Y., Linke, M., von Haimberger, T., Hahn, J., Matute, R., González, L., et al. (2012). Real-time tracking of phytochrome's orientational changes during Pr photoisomerization. J. Am. Chem. Soc. 134, 1408-1411. doi: 10.1021/ ja209413d

Yeh, K.-C., Wu, S.-H., Murphy, J. T., and Lagarias, J. C. (1997). A cyanobacterial phytochrome two-component light sensory system. Science 277, 1505-1508. doi: $10.1126 /$ science.277.5331.1505

Yu, D., Gustafson, W. C., Han, C., Lafaye, C., Noirclerc-Savoye, M., Ge, W.P., et al. (2014). An improved monomeric infrared fluorescent protein for neuronal and tumour brain imaging. Nat. Commun. 5:3626. doi: 10.1038/ ncomms 4626
Zanotti, J.-M., Bellissent-Funel, M. C., and Parello, J. (1999). Hydration-coupled dynamics in proteins studied by neutron scattering and NMR: the case of the typical EF-hand calcium-binding parvalbumin. Biophys. J. 76, 2390-2411. doi: 10.1016/S0006-3495(99)77395-9

Zhang, J. A., Wu, X. J., Wang, Z. B., Chen, Y., Wang, X., Zhou, M., et al. (2010). Fused-gene approach to photoswitchable and fluorescent biliproteins. Angew. Chem. Int. Ed. Engl. 49, 5456-5458. doi: 10.1002/anie.201001094

Ziegler, T., and Möglich, A. (2015). Photoreceptor engineering. Front. Mol. Biosci. 2:30. doi: 10.3389/fmolb.2015.00030

Conflict of Interest Statement: The authors declare that the research was conducted in the absence of any commercial or financial relationships that could be construed as a potential conflict of interest.

Copyright (C) 2015 Song, Lang, Kopycki, Hughes and Matysik. This is an open-access article distributed under the terms of the Creative Commons Attribution License (CC $B Y)$. The use, distribution or reproduction in other forums is permitted, provided the original author(s) or licensor are credited and that the original publication in this journal is cited, in accordance with accepted academic practice. No use, distribution or reproduction is permitted which does not comply with these terms. 